\title{
A SOCIALIZAÇÃO ORGANIZACIONAL DOS SERVIDORES DE UMA IFES: em tempos de REUNI
}

\author{
Diego César Terra de ANDRADE ${ }^{1}$ \\ Heidy Rodriguez RAMOS ${ }^{2}$ \\ Danielle Martins Duarte COSTA ${ }^{3}$ \\ Denis Renato de OLIVEIRA ${ }^{4}$
}

\begin{abstract}
${ }^{1}$ Doutorando em Administração, UNINOVE; Professor IFSULDEMINAS; diego.terra@ifsuldeminas.edu.br ${ }^{2}$ Doutora em Administração, FEA-USP; Professora UNINOVE; heidyr@ gmail.com

${ }^{3}$ Doutoranda em Engenharia de Produção, UNIFEI; Professor IFSULDEMINAS; danielle.costa@ifsuldeminas.edu.br

${ }^{4}$ Doutor em Administração, FEA/RP-USP; Professor UFLA; denisrenatodeoliveira@gmail.com
\end{abstract}

Recebido em: 25/08/2015 - Aprovado em: 03/05/2016 - Disponibilizado em: 30/07/2016

\begin{abstract}
RESUMO: Realizou-se esta pesquisa com servidores técnico-administrativos e docentes de uma Instituição Federal de Ensino Superior. O objetivo foi identificar a percepção dos servidores acerca do nível de socialização organizacional e sua variação, conforme o tempo de serviço na instituição. Sua fundamentação teórica baseia-se no enfoque dos Conteúdos e da Informação. O trabalho caracteriza-se como um estudo de caso descritivo e quantitativo. Os resultados indicaram a tendência de bom aproveitamento do quadro de pessoal da Universidade, considerando os níveis de socialização organizacional, como aferidos pelos sete fatores hipotéticos da pesquisa. Contudo, alguns índices podem ser melhorados por meio de estratégias de socialização.
\end{abstract}

PALAVRAS-CHAVE: Administração pública. Gestão de pessoas. REUNI. IFES. Socialização organizacional.

ABSTRACT: We conducted this research with technical and administrative staff and teachers of a Federal Institution of Higher Education. The objective was to identify the perception of the servers about the organizational socialization level and its variation as the service in the institution. Its theoretical foundation is based on the approach of Content and Information. The work is characterized as a study of descriptive and quantitative case. The results indicated a tendency to sound legacy of the University staff, considering the organizational socialization levels, as measured by the seven hypothetical factors research. However, certain indices can be improved by socialization strategies.

KEYWORDS: Organizational socialization. IFES. REUNI. Human resources. Public administration.

\section{INTRODUÇÃO}

Nas últimas décadas, observa-se que a sociedade vem passando por inúmeras transformações decorrentes de um novo contexto econômico, político e social. Nesse sentido, o setor público vem sendo obrigado a repensar sua forma de agir, buscando um modelo de gestão eficiente (BRESSERPEREIRA， 2001; MARINI， 2002;
MARTINS, 1997; MENDES; TEIXEIRA, 2000). Contudo, algumas especificidades, advindas de sua própria natureza, o diferem, em muito, de outros setores. Entre essas divergências, a finalidade, os meios utilizados para recrutamento, seleção e contratação, as políticas de remuneração, os métodos de avaliação de desempenho, entre outros, podem ser citados. 
Dessa forma, quando se fala em Gestão de Pessoas no setor público, faz-se necessário atentar para uma realidade diversa daquela já consagrada nas organizações privadas. De maneira geral, por exemplo, quando uma empresa do segundo setor seleciona uma pessoa para fazer parte do seu quadro de funcionários, espera-se que ela possa contribuir para aumentar os lucros da empresa. Por sua vez, quando uma organização do setor público realiza um concurso e empossa um novo servidor, ela espera que ele consiga aumentar os índices de eficiência, eficácia e efetividade, o que não necessariamente corresponde a lucro, e sim a uma melhor prestação de serviços à sociedade.

Nesse sentido, Oliveira et al. (2008) atentam que, no setor público, tal ênfase ganha uma conotação ética de preocupação com a aplicação de recursos públicos e a melhoria da prestação de serviços ao cidadão. Diante disso, Borges et al. (2010) afirmam que uma das respostas da Academia para tentar sanar tal problema foi intensificar as pesquisas sobre socialização organizacional, como uma ferramenta capaz de auxiliar a Gestão de Pessoas.

Dá-se o nome de socialização organizacional, de acordo com Shinyashiki (2003), a maneira como a organização recebe os funcionários e os integra à sua cultura, seu contexto e sistema, para que eles possam comportar-se de maneira adequada às expectativas da organização. Já Schein (1982) observa que o uso do termo socialização organizacional pode estar associado ao processo no qual um novo membro aprende os sistemas de valores, as normas e os padrões de comportamento demandados por uma organização ou pelo grupo no qual está ingressando. Motta (1993) afirma ainda que a socialização organizacional é um processo contínuo que se inicia antes mesmo da entrada do indivíduo na empresa e continua durante toda a sua permanência na organização.

Oliveira et al. (2008) realizaram na Universidade Federal do Rio Grande do Norte (UFRN), em 2005, um estudo utilizando o Inventário de Socialização Organizacional (ISO) composto de 54 itens. Entre as justificativas das autoras para tal pesquisa, estão, diretamente, os problemas de gestão de pessoas, tais como: a diferença de desempenho entre setores, centros e servidores; a existência de problemas de ordem geral, como a limitação dos recursos existentes, relacionados à infraestrutura básica de recursos financeiros, materiais e humanos.

Especificamente sobre esse contexto, verifica-se que as políticas educacionais no nível superior, em 2005, eram outras ${ }^{1}$. Dessa forma, observa-se a relevância de análises organizacionais no que tange à questão da socialização, no atual cenário da educação superior brasileira. Autores como Andrade et 
al. (2010) apontam mudanças significativas nas Instituições Federais de Ensino Superior (IFES) a partir de 24 de abril de 2007, quando foi lançado, pelo Governo Federal, o Plano de Desenvolvimento da Educação (PDE), que contém cerca de quatro dezenas de medidas, entre elas o Decreto $n^{\circ}$. 6.096, que instituiu o Programa de Apoio a Planos de Reestruturação e Expansão das Universidades Federais (REUNI) (BRASIL, 2009a).

O REUNI tem como objetivos gerais criar condições para a ampliação do acesso e permanência na educação superior, o aumento da qualidade dos cursos e melhor aproveitamento da estrutura física (investimento de quase 2,2 bilhões de reais) e de recursos humanos (previsão de contratação de 15.755 novos docentes e 13.564 novos técnicos administrativos, distribuídos de 2008 a 2012) existentes nas universidades (BRASIL, 2009b) [grifo nosso].

Dessa forma, a fim de levantar questões referentes à gestão de pessoas, mais especificamente no que tange à socialização organizacional, como uma ferramenta gerencial, este trabalho foi realizado em uma IFES, optante pelo Programa. Para ilustrar o quanto o REUNI está sendo impactante na IFES objeto do estudo deste trabalho, verificou-se que em 2006 ela ofertava 620 vagas, saltando em 2011 para 1480 novas matrículas anuais. E, como consequência do aumento do número de vagas ofertadas aos alunos, há o crescimento do número de docentes e técnicos administrativos, sendo, então, uma justificativa ao estudo realizado nesta pesquisa.

Diante desse contexto, levanta-se a hipótese de que, no caso desta Instituição, o processo de socialização não ocorrera de forma planejada; por exemplo, fatores culturais, históricos, físicos da IFES, bem como de personalidade e de alocação dos servidores não tenham sido trabalhados, o que pode contribuir negativamente com o fenômeno (VAN MAANEN, 1989).

Assim, tem-se a seguinte questão: Como se encontra o processo de socialização organizacional nesta instituição, segundo os grupos ocupacionais docentes e técnicoadministrativos? Desta forma, este trabalho possui os seguintes objetivos:

a. identificar a percepção dos servidores acerca do nível de socialização organizacional;

b. verificar se o nível de socialização organizacional varia conforme o tempo de serviço na instituição.

Para tanto foi utilizado o Inventário de Socialização Organizacional composto de 45 perguntas, divididas em sete fatores, e que, por ora, fora validado ao setor público brasileiro, conforme afirmam Borges et al. (2010). E, ainda, segundo a mesma autora, “esta versão do questionário é melhor do que 
aquela disponível anteriormente" (BORGES et al., 2010, p. 27).

\section{SOCIALIZAÇÃO ORGANIZACIONAL}

Sob o ponto de vista sociológico, a socialização é um processo contínuo no qual o indivíduo ao longo da vida aprende e identifica hábitos e valores característicos que o ajudam no desenvolvimento de sua personalidade e na integração ao seu grupo, tornando-o sociável, trazendo-lhes hábitos e valores que não lhes são inatos. Segundo Levy Junior (1973, p. 60), "em estado de isolamento social, o indivíduo não é capaz de desenvolver um comportamento humano, pois esse deve ser aprendido ao longo de suas interações com os grupos sociais". Nesse sentido, Chanlat et al. (1996, p. 36) afirmam que "o ser humano não vive em um círculo fechado, pois é na relação com o outro que o ego se constrói”.

\section{Durkheim (1987) ressalta a} importância da socialização ao mostrar que a sociedade só pode existir porque penetra no interior do ser humano, moldando sua vida, criando sua consciência, suas ideias e valores. Socializar-se implica o desenvolvimento de uma identidade diferenciadora, ao mesmo tempo em que a inclusão sócia histórica ao meio (construído) assemelha-se e identifica-se com os grupos de referência (BERGER; BERGER, 1977; BERGER; LUCKMANN, 2002, 2004; MARTIN-BARÓ, 1992;
TORREGROSA; VILLANUEVA, 1984). Tal processo, portanto, é dinâmico no sentido de que é contínuo e encerra a vivência de contradições existenciais. É um processo que se desenrola durante toda a vida do indivíduo (BORGES et al., 2010), ou seja, não é possível afirmar que ele possua um início, meio e fim.

Sob uma abordagem psicológica, e laboral, segundo Gontijo e Melo (2005) a socialização organizacional é tida como um processo de complexa descrição e condução, sobretudo pelo fato de envolver muitos elementos subjetivos, com implicações não apenas na vida profissional e educacional, como também em aspectos afetivos do indivíduo. Mesmo assim, o tema vem despertando o interesse de administradores, pesquisadores e outros profissionais há algum tempo (FELDMAN, 1976; SHINYASHIKI, 2000).

De acordo com Shinyashiki (2003), dá-se o nome de socialização organizacional à maneira como a organização recebe os funcionários e os integra à sua cultura, seu contexto e sistema, para que eles possam comportar-se de maneira adequada às expectativas da organização. Para Schein (1982), o uso do termo pode estar associado ao processo no qual um novo membro aprende os sistemas de valores, as normas e os padrões de comportamento demandados 
por uma organização ou pelo grupo no qual está ingressando.

Conforme expõe Shinyashiki (2003), os indivíduos passam por processos de socialização durante todas as etapas de sua vida, internalizando padrões de comportamento, normas e valores decorrentes do contex to no qual se encontram inseridos ou da situação social na qual estão vinculados. Trata-se de um processo contínuo que se inicia antes mesmo da entrada do indivíduo na empresa e continua durante toda a sua permanência na organização (MOTTA, 1993). Sendo assim, Oliveira et al. (2008a) classificam o processo de socialização organizacional em bidirecional e recíproco; primeiro, porque a adaptação é mútua, tendo em vista a busca de uma verdadeira simbiose entre as partes (organização/funcionário), e segundo, porque cada parte atua sobre a outra.

Em revisão bibliográfica, realizada por Borges e Albuquerque (2014), cronologicamente os estudos sobre socialização organizacional evoluíram sob quatro correntes distintas: a das táticas organizacionais; a desenvolvimentista; a dos conteúdos e da informação; e a das tendências integradoras. Ademais, em virtude dos objetivos desta pesquisa, cabe ênfase, aqui, ao enfoque dos conteúdos e da informação, pois, como exposto por Borges et al. (2010), o Inventário de Socialização Organizacional utilizado neste trabalho pertence a este enfoque.

De acordo com Borges et al. (2010), no enfoque dos conteúdos e da informação, a atenção se volta aos processos cognitivos do indivíduo, relacionando-os aos conteúdos do processo de socialização e ao papel da busca (pró) ativa de informações, abandonando a suposição de estágios sequenciais.

Oliveira et al. (2008) afirmam que as pesquisas sob esse enfoque consideram a proatividade dos indivíduos, entendendo que os iniciantes em uma organização são agentes ativos que buscam as pessoas e os locais de aprendizado, julgados como valiosos para facilitar o próprio ajustamento, sendo capazes de influenciar as normas do grupo e os resultados de desempenho. Já com relação ao conteúdo e informação, Ashforth et al. (2007), consiste em um conjunto de aspectos relacionados ao trabalho, os quais são considerados essenciais ao aprendizado de um indivíduo, para que esse possa se tornar um membro proficiente e se sentir confortável na organização. Ashforth et al. (2007) expõem, ainda, que existe um conjunto de aspectos relacionados ao trabalho que são considerados essenciais ao aprendizado do funcionário, para que ele possa se tornar um membro capaz e, assim, se sinta adaptado à organização.

Nesse sentido, Carvalho (2009) afirma que o domínio das tarefas envolve fatores, 
como

deveres

$\mathrm{e}$

obrigações,

responsabilidades, prioridades, modo de usar equipamentos e de lidar com questões de rotina. Os papéis de trabalho focam os limites da autoridade e da responsabilidade, as expectativas e os comportamentos adequados ao posto. Os processos de grupo referem-se à interação com os colegas, às normas e valores do grupo e à estrutura normativa do grupo de trabalho. Por fim, os atributos organizacionais dizem respeito às políticas, ao poder, ao conjunto de valores do sistema organizacional, à missão e ao estilo de liderança. Segundo a mesma autora, os resultados do estudo encampados sob esse enfoque indicaram, ainda, que a aquisição de informações sobre o domínio da tarefa, dos papéis e dos processos de grupo tende a ser mais importante durante as experiências iniciais no emprego do que a aquisição de informações relacionadas aos atributos organizacionais.

Oliveira et al. (2008) afirmam que algumas das tipologias, nessa corrente, incluíram escalas para mensurar a aquisição de conteúdo. Carvalho (2009) cita alguns exemplos de trabalhos que incluem essas escalas, tais como:

a. Ostroff e Kozlowski (1992), que apresentaram uma medida de socialização organizacional que envolve quatro domínios de conteúdo: tarefas do emprego, papéis de trabalho, processos de grupo e atributos organizacionais.

b. Morrison (1995), para construir sua escala, integrou várias tipologias para derivar sete domínios de conteúdo (informação técnica sobre como executar as tarefas; informação de atribuições sobre as requisições e expectativas do papel de trabalho; informação social sobre outras pessoas e os relacionamentos com elas; informação avaliativa sobre como o desempenho e o comportamento estão sendo apreciados por outros na organização; informação normativa sobre a cultura organizacional; informação organizacional sobre a estrutura, procedimentos, produtos/serviços e resultados da empresa; e informação política sobre a distribuição de poder dentro da organização).

c. Taormina (1997) apresenta um modelo de socialização organizacional como um processo contínuo envolvendo quatro domínios, os quais, por sua vez, incluem quatro áreas de conteúdo que operam de forma contínua e interativa umas com as outras (treinamento; entendimento; suporte proporcionado por colegas de trabalho; e perspectivas de futuro).

d. Haueter, Macan e Winter (2003) propõem a escala de três dimensões, a saber: organização, grupo, e tarefa.

Ademais, segundo Carvalho (2009), um dos mais conhecidos trabalhos sob esta 
corrente e tipologia é o de Chao et al. (1994). Esse autor defende a existência de seis domínios de conteúdo da socialização organizacional (Quadro 1).

Quadro 1: Domínios de conteúdo da socialização organizacional.

\begin{tabular}{|c|c|}
\hline $\begin{array}{l}\text { Proficiência de } \\
\text { desempenho }\end{array}$ & $\begin{array}{l}\text { Avalia a extensão nas quais } \\
\text { indivíduos dominam suas tarefas. }\end{array}$ \\
\hline Pessoas & $\begin{array}{l}\text { Envolve a satisfação nas relações com } \\
\text { membros da organização. }\end{array}$ \\
\hline Polít & $\begin{array}{l}\text { Abrange o sucesso de um indivíduo } \\
\text { em obter informações com respeito às } \\
\text { relações de trabalho formais e } \\
\text { informais e às estruturas de poder } \\
\text { dentro da organização. }\end{array}$ \\
\hline História & $\begin{array}{l}\text { Diz respeito ao conhecimento das } \\
\text { tradições, costumes, mitos e rituais } \\
\text { que compõem a cultura da } \\
\text { organização. }\end{array}$ \\
\hline Linguagem & $\begin{array}{l}\text { Aborda o conhecimento do indivíduo } \\
\text { sobre a linguagem técnica } \\
\text { profissional, bem como a } \\
\text { familiaridade com a linguagem } \\
\text { informal da organização. }\end{array}$ \\
\hline $\begin{array}{l}\text { Objetivos e } \\
\text { valores } \\
\text { organizacionais }\end{array}$ & $\begin{array}{l}\text { Compreende a interiorização das } \\
\text { regras ou princípios que mantêm a } \\
\text { integridade da organização. }\end{array}$ \\
\hline
\end{tabular}

Fonte: Adaptado de Chao et al. (1994).

Oliveira et al. (2008) explicam ainda que Chao et al. (1994), em seus estudos, observaram também que, normalmente, as pessoas bem socializadas em seus papéis organizacionais têm maiores rendimentos pessoais, são mais satisfeitas, mais envolvidas com suas carreiras, mais adaptáveis e têm um melhor senso de identidade pessoal, comparativamente às menos socializadas.

\section{CONTEXTO E RELÊVANCIA DA PESQUISA}

No Brasil, no segundo semestre de 2006, inicia-se uma campanha contra o atual formato do ensino ministrado na maioria das universidades, com diagnósticos e análises variados, baseados em dados estatísticos das vagas nas universidades públicas e das altas taxas de evasão no ensino superior. A proposta apresentada para se contrapor a esse quadro teve, na ocasião, como principal interlocutor o reitor da Universidade Federal da Bahia (UFBA), professor Naomar Monteiro de Almeida Filho, que, em inúmeras visitas, aulas inaugurais e palestras, divulgou a chamada "Universidade Nova" como a solução contra a obsolescência das universidades de modelo tradicional (LÉDA; MANCEBO, 2009).

Em apresentação no seminário intitulado "Universidade Nova: Reestruturação da Arquitetura Acadêmica da UFBA", o Professor Naomar, afirma que:

[...] a ideia de estudos superiores de graduação de maior amplitude e não comprometida com uma profissionalização precoce e fechada, bem como maior integração entre esses 
estudos e os de pósgraduação, já é realidade em muitos países social e economicamente desenvolvidos. O processo europeu de Bolonha é um exemplo eloquente dessa concepção acadêmica que, por força das demandas da Sociedade do Conhecimento e de um mundo do trabalho marcado pela desregulamentação,

flexibilidade

$\mathrm{e}$ imprevisibilidade, certamente se consolidará como um dos modelos de educação superior de referência para o futuro próximo[...]

(UNIVERSIDADE FEDERAL DA BAHIA UFBA, 2007, p. 17).

Portanto, conclui-se que a proposta denominada "Universidade Nova" possui evidente similaridade com processo europeu, denominado Declaração de Bolonha. No Brasil, de acordo com Léda e Mancebo (2009), a possibilidade de materialização desse modelo, em âmbito nacional, vem com a publicação do Decreto $n^{\circ}$. 6.096. Em seu artigo $1^{\circ}$ define o objetivo do REUNI:

Art. $1^{\circ}$ Fica instituído o Programa de Apoio a Planos de Reestruturação e Expansão das Universidades Federais - REUNI, com o objetivo de criar condições para a ampliação do acesso e permanência na educação superior, no nível de graduação, pelo melhor aproveitamento da estrutura física e de recursos humanos existentes nas universidades federais (BRASIL, 2009a, p. 1).

São metas e diretrizes gerais do Programa:

a. Aumentar a qualidade do ensino por meio da inovação e adequação acadêmicas com a articulação entre graduação, pósgraduação e educação básica, profissional e tecnológica;

b. Elevar, de forma gradual, a taxa de conclusão média dos cursos de graduação presenciais para $90 \%$ e atingir a taxa da relação aluno/professor em cursos presenciais de graduação igual a 18;

c. Aumentar em pelo menos $20 \%$ as matrículas nos cursos de graduação;

d. Prazo de cinco anos, a contar do início de cada plano, para o cumprimento das metas estabelecidas pelas instituições federais de ensino superior.

$\mathrm{O}$ Artigo $5^{\circ}$ diz que: "O ingresso no Programa poderá ser solicitado pela IFES, a qualquer tempo, mediante proposta instruída”, ou seja, sua adesão é facultativa; contudo, como já exposto, as 54 Universidades Federais existentes em 2007 entraram no Programa (BRASIL, 2009a), inclusive a Instituição pesquisada.

Relativo, especificamente, aos Recursos Humanos, em julho de 2007, a Instituição Federal de Ensino Superior 
Pesquisada (IFESP), no período imediatamente posterior à sua adesão ao Programa do Decreto ${ }^{\circ}$. 6.096, contabilizava em seu quadro de servidores, 356 professores e 237 servidores técnico-administrativos, sendo 59 com nível superior $(24,89 \%)$ e os demais de nível intermediário ou auxiliar (IFESP, 2011).

A partir de 2008, novos servidores, docentes e servidores técnico-administrativos, foram empossados, conforme Quadro 2. Contudo, cabe ressaltar que algumas dessas contratações são frutos de reposição de pessoal (banco de equivalentes) e principalmente aposentadorias.

Quadro 2: Contratações de servidores técnicoadministrativos e docentes a partir de 2008 na IFES pesquisada.

\begin{tabular}{|l|l|l|l|}
\hline Ano/Servido & $\begin{array}{l}\text { Técnico } \\
\text { Administrativ } \\
\text { o - Nível D }\end{array}$ & $\begin{array}{l}\text { Técnico } \\
\text { Administrativ } \\
\text { o - Nível E }\end{array}$ & Docente \\
\hline $\mathbf{2 0 0 8}$ & 14 & 10 & 20 \\
\hline $\mathbf{2 0 0 9}$ & 16 & 15 & 53 \\
\hline $\mathbf{2 0 1 0}$ & 15 & 15 & 61 \\
\hline $\mathbf{2 0 1 1}$ & 45 & - & 62 \\
\hline $\mathbf{2 0 1 2}$ & 39 & - & 29 \\
\hline Total & $\mathbf{1 2 9}$ & $\mathbf{4 0}$ & $\mathbf{2 2 5}$ \\
\hline
\end{tabular}

Fonte: Dados fornecidos pelo departamento de Gestão de Pessoas da IFESP (2011).
Este aumento no quadro de servidores vem a dar suporte à expansão do número de vagas oferecidas nos cursos da IFESP, que em 2006 eram de 620 vagas, e que em 2011, já era da ordem de 1480 novas matriculas (Tabela 1).

Tabela 1 - Evolução das vagas de ingresso nos processos seletivos da IFES pesquisada de 2007 a 2011.

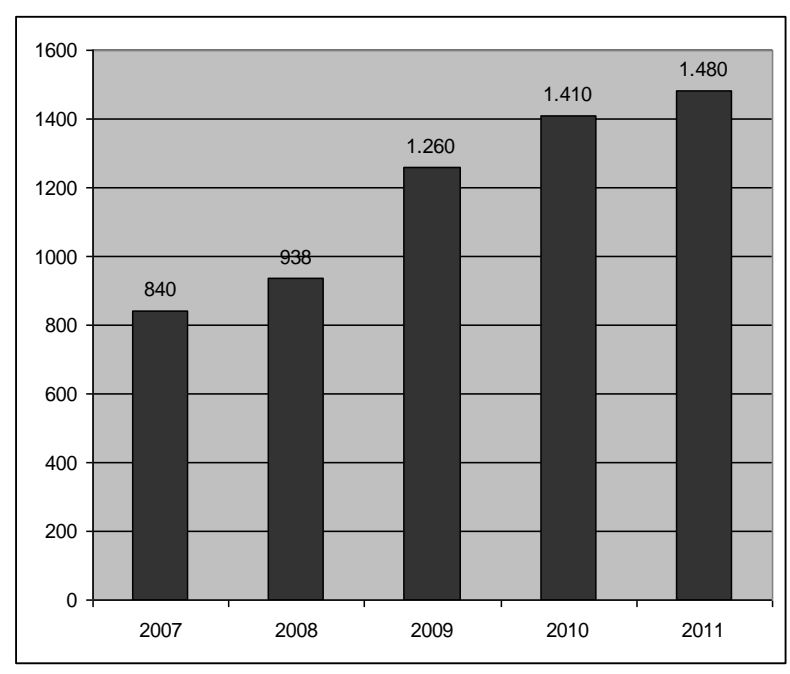

Fonte: IFESP (2011).

Segundo dados obtidos em material de divulgação da IFESP, essa expansão vem sendo acompanhada de modificações estruturais e pedagógicas, para assim serem sustentadas (IFESP, 2011), como exemplo, a construção de prédios, pavilhões de aulas, laboratórios, centros de convivência estudantil, reformulações das diretrizes e planos de cursos entre outras. Conclui-se, a partir de tais observações e frente ao histórico de expansão da IFESP, que o momento atual é sem precedentes em sua história. 


\section{PROCEDIMENTOS METODOLÓGICOS}

A pesquisa caracteriza-se por ser de campo e de caráter descritivo. Nessa ótica, Triviños (1987, p. 110) afirma que a pesquisa de cunho descritivo relata a ocorrência dos fatos na realidade investigada. As pesquisas descritivas não consideram somente os dados da "coleta e da classificação dos dados", podem estabelecer relações entre as variáveis nas pesquisas desse tipo, sendo caracterizado como estudo descritivo e correlacional. Quanto aos meios, foi realizado um estudo de caso. Para Yin (2001), a característica do estudo de caso é de investigação empírica, tendo como objetivo a percepção da manifestação do estudo no seu âmbito da "vida real". Mediante os objetivos e questão de pesquisa deste estudo utilizou-se para o levantamento dos dados um questionário estruturado do tipo survey, conforme descrito por Cervo e Bervian (1996), Lakatos e Marconi (1995) e Mattar (1999).

A Universidade, unidade de análise, é uma instituição de ensino com mais de um século de existência, localizada no interior de Minas Gerais, fundada no início do século dezenove por missionários americanos. Tornou-se, no ano de 1938, escola superior; foi federalizada em 1963 e manteve sua vocação voltada ao ensino das Ciências Agrárias. Em 1994, a IFESP tornou-se uma Universidade Federal.
Como os atos de provimento não param, necessitou-se estipular um limite de tempo para definição da população pesquisada. Sendo esse tempo a data do efetivo exercício do servidor ter ocorrido até 31 de dezembro de 2010. Portanto, o universo da pesquisa é composto por 815 elementos. Esses elementos são servidores, na ativa e concursados, da Instituição Federal de Ensino Superior Pesquisada (IFESP). Desse quantitativo, têm-se os servidores técnicoadministrativos, distribuídos na seguinte classificação (Quadro 3):

Quadro 3: Nível de classificação dos técnicos administrativos da IFES pesquisada.

\begin{tabular}{|l|l|l|}
\hline $\begin{array}{l}\text { Nível de } \\
\text { Classificação }\end{array}$ & Quantidade & Percentual \\
\hline E & 106 & $30,54 \%$ \\
\hline D & 172 & $49,56 \%$ \\
\hline C & 60 & $17,29 \%$ \\
\hline B & 6 & $1,72 \%$ \\
\hline A & 3 & 0,86 \\
\hline TOTAL & $\mathbf{3 4 7}$ & $\mathbf{1 0 0 \%}$ \\
\hline
\end{tabular}

Fonte: Dados fornecidos pelo departamento de Gestão de Pessoas da IFESP (2011).

Os 468 elementos restantes da pesquisa são docentes. Estes estão divididos de acordo com a seguinte classe (Quadro 4): 
Quadro 4: Classe dos Docentes da IFES pesquisada

\begin{tabular}{|l|l|l|}
\hline Classe & Quantidade & Percentual \\
\hline Professor Adjunto & 234 & $50,00 \%$ \\
\hline Professor Assistente & 27 & $5,77 \%$ \\
\hline Professor Associado & 143 & $30,56 \%$ \\
\hline $\begin{array}{l}\text { Professor do Ensino Básico, } \\
\text { Técnico e Tecnológico } \\
\text { EBTT) }\end{array}$ & & $1,92 \%$ \\
\hline Professor Titular & 55 & $11,75 \%$ \\
\hline TOTAL & $\mathbf{4 6 8}$ & $\mathbf{1 0 0 , 0 0 \%}$ \\
\hline
\end{tabular}

Fonte: Dados fornecidos pelo departamento de Gestão de Pessoas da IFESP (2011).

Para definição do tamanho da amostra, levaram-se em consideração os valores estimados para $\mathrm{p}=0,5$ e Intervalo de Confiança (IC) de 95\%, considerando o Fator de Correção para Populações Finitas, calculado pela fórmula $(\mathrm{N}-\mathrm{n}) / \mathrm{N}$, em que $\mathrm{N}$ é o tamanho da população, e n, o tamanho da amostra (COCHRAN, 1965). Seguindo esses parâmetros, o número mínimo de respostas exigido para a população de 815 servidores é de 261 participações. A amostra final dessa pesquisa foi composta de 289 servidores respondentes, sendo dividida em 192 docentes $(66,4 \%)$ e 97 técnicos administrativos $(33,6 \%)$.

Quanto ao instrumento de pesquisa, utilizaram-se o questionário do Inventário de Socialização Organizacional, que, como já elucidado e, de acordo com Borges et al. (2010), é baseado na pesquisa de autoria de Chao et al. (1994). Sendo que, desta pesquisa, uma primeira versão fora adaptada, no Brasil, de uma amostra de trabalhadores da construção civil e de uma rede de supermercados, por Borges, Ros e Tamayo, no ano de 2001 (BORGES et al., 2010). Em 2005, Borges, em trabalho não publicado, redigiu novamente os itens do Inventário, adaptando-o à linguagem cotidiana dos participantes. Para levantar o linguajar típico, a autora utilizou a fala de servidores da (UFRN) em entrevistas concedidas por 12 servidores (BORGES et al., 2010). A próxima etapa foi a realização de um teste com especialistas (seis participantes) por meio do qual se avaliou a adequação dos itens para a mensuração dos fatores hipotéticos (GÜNTHER, 1999; PASQUALI, 1997, 1999 apud BORGES et al., 2010). Desses participantes, três eram professores do Departamento de Psicologia, da área de Psicologia Social da UFRN, e três eram professores da Universidade Complutense de Madrid. Ainda, segundo as autoras, tal teste foi importante para o aperfeiçoamento da redação dos vários itens e eliminação de outros tantos.

Os itens eliminados foram os que maiores divergências, entre os participantes, apresentaram. Quando as divergências eram mais localizadas, ou seja, em um ou dois dos participantes, a autora trabalhou no aperfeiçoamento dos itens. Por fim, o inventário ficou com 54 itens, dispostos em 
uma escala tipo Likert, variando de -2 (discordo muito) a +2 (concordo muito). A escala empregada é a mesma utilizada desde a versão estadunidense sugerida por Chao et al. (1994) (BORGES et al., 2010).

Como já comentado, esse questionário de 54 itens foi utilizado pela primeira vez no Brasil, em 2005, por Oliveira et al. (2008), em pesquisa na UFRN. Uma última versão foi apresentada por Borges et al. (2010), que após análises estatísticas, sua adaptação e validação à administração pública brasileira culminou no ISO, composto de 45 itens e sete fatores hipotéticos, a saber:

a. Acesso a Informações (Políticas) - Acessar informações, saber sobre datas importantes, processos organizacionais, critérios e poder.

b. Competência e Proatividade - Ser apto para criar, ser eficaz, produtivo, ativo para buscar informações.

c. Integração com as Pessoas - Sentir-se aceito pelos outros, incluído na equipe, na organização e participar no processo de tomada de decisão.

d. Não Integração com a Organização Ausência do domínio da linguagem, do emprego, do conhecimento sobre os processos organizacionais e da cultura organizacional.

e. Qualificação Profissional - Conhecimento e experiência profissional. Domínio da linguagem profissional e tarefas. f. Objetivos e Valores Organizacionais Conhecer e identificar-se com objetivos e prioridades organizacionais. Conhecer a história organizacional.

g. Linguagem e Tradição - Dominar a linguagem profissional e organizacional. Conhecer tradições e histórias dos colegas. Saber identificar as pessoas mais influentes.

Cabe ressaltar que, de acordo com Borges et al. (2010), esses fatores apresentaram os coeficientes do alfa de Cronbach $(\alpha)$ entre 0,70 e 0,83 (todos acima do ponto de corte aceito pelo Conselho Federal de Psicologia) e capacidade da variância explicada de 47,68\%. De acordo com as autoras, isso indica que essa versão do questionário é melhor do que aquela disponível anteriormente. Portanto, essa foi a versão utilizada no presente trabalho.

Com relação à coleta dos dados, foram utilizados os serviços do programa on-line SurveyMonkey, que é uma ferramenta de criação e distribuição de questionários via web. A coleta das informações necessárias à realização do estudo ocorreu em três etapas, envolvendo os grupos constituintes da amostra do estudo (servidores técnicoadministrativos e docentes da IFES, empossados até 31 de dezembro de 2010). Sendo realizada nos dias 12 de abril, 16 de maio e 5 de julho de 2011. Nessas ocasiões, foram encaminhadas mensagens eletrônica 
aos endereços de e-mail institucional dos participantes da pesquisa, contendo um link de acesso ao Inventário de Socialização Organizacional.

Para as análises dos dados, as respostas dos participantes foram baixadas do site SurveyMonkey e, em seguida, submetidas as rotinas estatísticas descritivas disponíveis no Software Statistical Package of Social Sciences (SPSS) para Windows versão 17.0.

Como o ISO é uma escala composta por sete fatores (multifatorial), seus resultados foram apurados fator por fator. Assim, se obteve um resultado (ou média fatorial) para cada um dos fatores, ou seja, o diagnóstico da socialização organizacional da IFES foi feita baseando-se nos sete fatores, como já apresentado, pelo trabalho de Borges et al. (2010). Por exemplo, para o Fator 1, Acesso a Informações (Políticas), utilizou-se apenas as respostas dos itens 37, 38, 41, 42 e 47.

Para interpretar as médias das bases, considerou-se que quanto maior for o valor da média fatorial, maior é o grau de socialização organizacional, na Instituição, neste fator. Assim, valores entre 3,8 e 5 indicam o maior grau de socialização organizacional. Por outro lado, valores entre 1 e 2,3 tendem a sinalizar menores graus de socialização, enquanto valores entre 2,4 e 3,7 informam um estado mediano quanto a socialização organizacional neste construto.
Para verificar se o nível de socialização organizacional varia conforme o tempo de serviço na instituição aferiu-se o tempo médio de serviço da amostra na instituição e seu desvio-padrão, para, então, realizar uma correlação entre esses dados e os escores nos fatores de socialização organizacional, pelo método de Pearson. Bagozzi, Yi e Philipps (1991), afirmam que o método de correlação de Pearson é uma das técnicas indicadas quando se quer comparar a associação existente entre dois conjuntos de dados.

\section{RESULTADOS}

Pelas médias e medidas de dispersão (desvio-padrão, mínimo e máximo), os escores por fator dos participantes foram sintetizados conforme Tabela 1. Dessa forma, coerentemente ao objetivo, que é identificar a percepção dos servidores da instituição pesquisada acerca do nível de socialização organizacional, a primeira observação a ser feita é que, em média, os servidores se percebem como bem socializados na maioria dos fatores mensurados, confirmado pelas baixas diferenças significativas entre as médias e levando-se em consideração os respectivos desvios-padrão. 
Tabela 1: Análises descritivas dos fatores do Inventário de Socialização Organizacional na amostra pesquisada

\begin{tabular}{|c|c|c|c|c|c|c|}
\hline o & $\left|\begin{array}{ll}\text { Fatores } & \text { do }\end{array}\right| \begin{array}{l}\mathbf{N} \\
\text { ISO }\end{array}$ & Míni & Máxi & Méd & $\begin{array}{l}\text { Desvi } \\
\text { p- } \\
\text { padrã } \\
\text { o }\end{array}$ & $\begin{array}{l}\text { Alpha } \\
\text { de } \\
\text { Cronba } \\
\text { ch }\end{array}$ \\
\hline 1 & \begin{tabular}{|l|l} 
Acesso a & 28 \\
Informações & 9 \\
(Políticas) & 9
\end{tabular} & 1 & 5 & 3,76 & 0,93 & 0,764 \\
\hline 2 & \begin{tabular}{|l|l} 
Competênci & \\
a & 28 \\
Proatividade & 9
\end{tabular} & 1,30 & 5 & 4,35 & 0,66 & 0,828 \\
\hline 3 & \begin{tabular}{|l|l} 
Integração & 28 \\
com & as \\
Pessoas & 9
\end{tabular} & 1 & 5 & 4,01 & 0,94 & 0,835 \\
\hline 4 & \begin{tabular}{|l|l} 
Não & \\
Integração & 28 \\
com & a 9 \\
Organização
\end{tabular} & 1 & 5 & 4,37 & 0,89 & 0,705 \\
\hline 5 & \begin{tabular}{|l|l} 
Qualificação & 28 \\
Profissional & 9
\end{tabular} & 1,33 & 5 & 4,41 & 0,70 & 0,641 \\
\hline 6 & \begin{tabular}{|l|l} 
Objetivos e & \\
Valores & 28 \\
Organizacio & 9 \\
nais &
\end{tabular} & 1 & 5 & 4,11 & 0,80 & 0,810 \\
\hline 7 & \begin{tabular}{l|l} 
Linguagem e & 28 \\
Tradição & 9
\end{tabular} & 1 & 5 & 3,93 & 0,98 & 0,778 \\
\hline
\end{tabular}

Fonte: Dados da pesquisa.

Destacam-se positivamente os escores médios dos fatores: Qualificação Profissional (Média de 4,41), Não Integração com a Organização ${ }^{2}$ (Média de 4,37), Competência e Proatividade (Média de 4,35), Objetivos e Valores Organizacionais (Média de 4,11) e Integração com as Pessoas (Média 4,01), todos com médias entre 4,00 e 5,00. Contudo, quando se leva em consideração os desviospadrão desses fatores, que também se apresentaram moderadamente baixos (máximo 0,94), percebe-se que existe certa população moderadamente socializada dentro da organização. Neste sentido destacam-se os fatores Integração com as Pessoas e Objetivos e Valores Organizacionais, ambos com escores próximos ao ponto neutro $(3,00)$.

Negativamente apresentam-se os escores médios dos fatores: Linguagem e Tradição (Média de 3,93) e Acesso a Informações (Políticas) (Média de 3,76). Este fato é agravado, e deve ser observado com atenção pelo departamento de Gestão de Pessoas da IFESP, pois os desvios-padrão desses fatores estão entre os mais altos observados $(0,98$ e 0,93 , respectivamente). Essas observações vêm a confirmar o que é apontado por Carvalho (2009), que expõe que as “informações relacionadas aos atributos organizacionais são menos importante para quem está iniciando, se comparado a outros aspectos do emprego" (CARVALHO, 2009, p.101).

Cabe observar, ainda, que o resultado do alpha de Cronbach desses fatores encontram-se entre 0,641 e 0,835, o que se constitui um resultado satisfatório, pois todos estão acima do ponto de corte aceito pelo Conselho Federal de Psicologia. 
Com relação ao objetivo de verificar se o nível de socialização organizacional varia conforme o tempo de serviço na instituição, observaram-se que o tempo médio de serviço da amostra é de 12,03 anos, com desviopadrão de 11,32, variando de menos de um ano de serviço a 46 anos. A mediana da amostra em tal variável é 6,00. Portanto, apesar da amplitude da variação do tempo de serviço na instituição, a maioria dos participantes da pesquisa possui pouco tempo de trabalho na instituição, já que a mediana é muito baixa, conforme apresentado pela Figura 2:

Figura 2. Ano de admissão dos servidores docente e técnico administrativo na IFES estudada, em percentual.

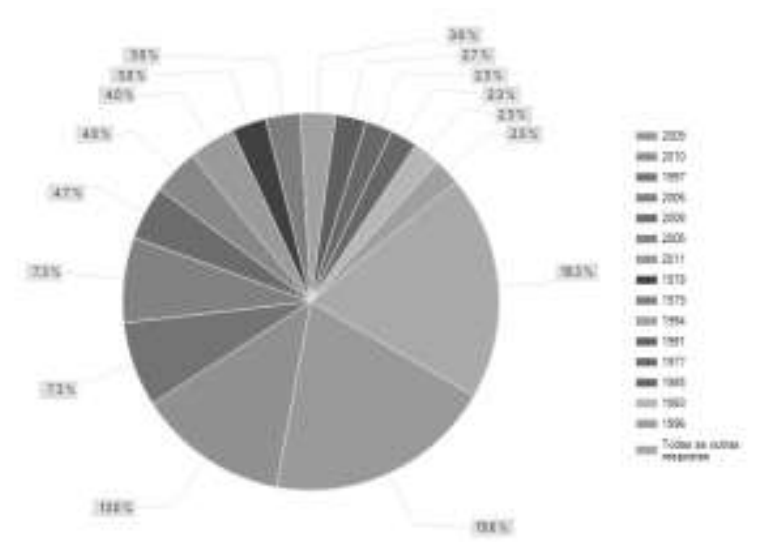

Fonte: dados da pesquisa.

Estimaram-se então, os coeficientes de correlação de Pearson entre os escores dos fatores de socialização organizacional e os tempos de serviço na instituição, conforme Tabela 2.
Dessa forma, constata-se que dois fatores apresentam correlações estatisticamente significativas a $1 \%(\mathrm{p}<0,001)$ e positivas com o tempo de serviço na instituição, embora com magnitudes modestas, sendo eles: Acesso a Informações (Políticas) (r=0,088) e Linguagem e Tradição $(r=0,79)$. Tais correlações indicam que quanto mais tempo na instituição, mais se compreende sobre a política adotada na instituição, entende-se onde se deve ir e/ou dirigir-se para obter informações, aprende-se mais sobre as gírias e semântica das palavras utilizadas, bem como se conhece sua história e tradições. Essa observação vem a corroborar os resultados apresentados na avaliação geral do nível de socialização, pois estes foram exatamente os mesmos fatores apontados na avaliação dos escores de todos os fatores. Contudo, também cabe observar que, o fator Competência e Proatividade apresentou correlação negativa e significativa $(r=-0,248$ para $\mathrm{p}<0,001)$, o que requer atenção dos gestores da IFESP. 
Tabela 2: Correlações entre os fatores de socialização organizacional e o tempo de trabalho dos servidores na IFES pesquisada.

\begin{tabular}{|c|c|c|c|}
\hline $\mathbf{N}^{\mathbf{o}}$ & Fatores do ISO & $\begin{array}{|ll|}\text { Teste } & \text { de } \\
\text { Pearson } & \end{array}$ & Resultado \\
\hline \multirow{3}{*}{1} & \multirow{3}{*}{$\begin{array}{l}\text { Acesso a Informações } \\
\text { (Políticas) }\end{array}$} & $\begin{array}{l}\text { Correlação de } \\
\text { Pearson }\end{array}$ & $0,088^{*}$ \\
\hline & & Sig. (bicaudal) & 0,167 \\
\hline & & $\mathrm{N}$ & 289 \\
\hline \multirow{3}{*}{2} & \multirow{3}{*}{$\begin{array}{l}\text { Competência } \\
\text { Proatividade }\end{array}$} & $\begin{array}{l}\text { Correlação de } \\
\text { Pearson }\end{array}$ & $-0,248^{*}$ \\
\hline & & Sig. (bicaudal) & 0,001 \\
\hline & & $\bar{N}$ & 289 \\
\hline \multirow{3}{*}{3} & \multirow{3}{*}{$\begin{array}{l}\text { Integração } \\
\text { Pessoas }\end{array}$} & $\begin{array}{l}\text { Correlação de } \\
\text { Pearson }\end{array}$ & $-0,122$ \\
\hline & & Sig. (bicaudal) & 0,115 \\
\hline & & $\mathrm{N}$ & 289 \\
\hline \multirow{3}{*}{4} & \multirow{3}{*}{$\begin{array}{l}\text { Não Integração com a } \\
\text { Organização }\end{array}$} & $\begin{array}{l}\text { Correlação de } \\
\text { Pearson }\end{array}$ & 0,004 \\
\hline & & Sig. (bicaudal) & 0,946 \\
\hline & & $\mathrm{N}$ & 289 \\
\hline \multirow{3}{*}{5} & \multirow{3}{*}{$\begin{array}{l}\text { Qualificação } \\
\text { Profissional }\end{array}$} & \begin{tabular}{|l} 
Correlação de \\
Pearson
\end{tabular} & 0,095 \\
\hline & & Sig. (bicaudal) & 0,147 \\
\hline & & $\mathrm{N}$ & 289 \\
\hline \multirow{3}{*}{6} & \multirow{3}{*}{$\begin{array}{l}\text { Objetivos e Valore } \\
\text { Organizacionais }\end{array}$} & $\begin{array}{l}\text { Correlação de } \\
\text { Pearson }\end{array}$ & 0,321 \\
\hline & & Sig. (bicaudal) & 0,189 \\
\hline & & $\mathrm{N}$ & 289 \\
\hline \multirow{3}{*}{7} & \multirow{3}{*}{ Linguagem e Tradição } & \begin{tabular}{|l|} 
Correlação de \\
Pearson
\end{tabular} & $0,79^{*}$ \\
\hline & & Sig. (bicaudal) & 0,97 \\
\hline & & $\widehat{N}$ & 289 \\
\hline
\end{tabular}

Fonte: Dados da pesquisa.

Todavia, de uma maneira geral, os resultados apoiam a afirmação, feita por
Motta (1993, p. 26), de que "a socialização organizacional é um processo contínuo que perdura durante toda a permanência do indivíduo na organização". Desta forma, neste caso especifico, verifica-se a necessidade do Departamento de Gestão de Pessoas lançar mão de estratégias de instrução, com a finalidade de orientar seus servidores, principalmente os mais novos (2 anos ou menos de instituição), quanto às questões relativas aos fatores Acesso a Informações (Políticas), Linguagem e Tradição e, ainda, buscar compreender porque o nível do fator Competência e Proatividade cai com o passar do tempo. Estas ações poderão resultar em maior eficiência, eficácia e efetividade ao trabalho dos professores e técnicos da IFESP, com consequências positivas à sociedade.

\section{DISCUSSÃO E CONSIDERAÇÕES FINAIS}

No presente trabalho propôs-se examinar o nível de socialização organizacional em uma Instituição Federal de Ensino Superior, segundo os grupos ocupacionais docentes e técnicoadministrativos, tendo em vista o atual contexto da educação superior brasileira em tempos de REUNI. Sob a hipótese de que, diante do expressivo número de novos servidores em curto espaço de tempo, resultado da expansão promovida pelo Decreto $n^{\circ}$. 6.096, o processo de socialização 
organizacional na IFES tende a ser mal sucedido. E, em busca de um entendimento mais amplo acerca do fenômeno, verificou-se, também, se o nível de socialização organizacional varia conforme o tempo de serviço dos servidores na instituição.

Para alcançar esses propósitos, utilizou-se um Inventario de Socialização Organizacional, composto de 45 itens, validado ao setor público brasileiro por Borges et al. (2010). A coleta de dados da pesquisa ocorreu entre os dias 12 de abril e 27 de julho de 2011 e os questionários foram respondidos por 289 servidores.

O estudo empreendido possibilitou algumas observações relevantes. A primeira delas refere-se ao fato de que há tendência geral a uma socialização eficaz na Instituição pesquisada, frente às médias obtidas para os fatores mensurados e os diferentes perfis, com destaque aos fatores hipotéticos: Competência e Proatividade, Integração com as Pessoas, Não Integração com a Organização, Qualificação Profissional, Objetivos e Valores Organizacionais. Essas conclusões já negam a hipótese inicial do trabalho de que o processo de socialização organizacional na IFESP seja mal sucedido frente à sua urgência, e esta é a principal contribuição teórica deste trabalho.

\begin{tabular}{cccc} 
Não & \multicolumn{2}{c}{ obstante as diferenças } \\
significativas & nos fatores & Acesso & a \\
Informações & (Políticas) e Linguagem & e
\end{tabular}
Tradição, merecedores de atenção por parte dos gestores, pois ambos apresentaram escores baixos, desses, o fator Acesso a Informações (Políticas) destaca-se ainda mais negativamente, por apresentar desvio-padrão elevado e pelo seu baixo escore alcançado.

Quanto à correlação entre o tempo de serviço e os fatores de socialização organizacional, constatou-se que os mesmos fatores apontados anteriormente (Acesso a Informações (Políticas) e Linguagem e Tradição) como os mais necessitados de atenção, por parte do Departamento de Gestão de Pessoas, pois possuem correlações estatísticas positivas. Tais correlações indicam que, quanto mais tempo na instituição mais se compreende sobre a política adotada na instituição, mais se conhece sobre sua história, mais se entende sobre o seu linguajar e suas tradições. Entretanto, uma constatação preocupante foi a de que, entre os servidores técnicoadministrativos e professores, o fator Competência e Proatividade apresentou correlação negativa e significativa. Isso pode indicar que, ao adentrar na organização, o indivíduo já se sente competente, e não percebe crescimento ou aumento de sua eficiência ao longo do tempo de trabalho. Pode-se inferir que esse é um processo latente aos servidores que não buscam formação complementar, seja porque são professores doutores, seja pelo fato de o técnicoadministrativo não mudar, por exemplo, do 
nível "D" para "E" ao obter uma graduação, em face da falta de uma política atrativa de cargos e salários. Ainda, com relação à proatividade, pode se interpretar que a estabilidade da carreira pública reduz a busca por qualidade por parte dos servidores na amostra estudada.

Mas, de forma geral, ainda em se tratando da correlação tempo, os outros itens dos fatores apresentaram-se positivos apesar dos diferentes níveis de significância. Ou seja, com o passar do tempo na instituição, o nível de socialização aumenta. A exceção foi observada no fator Integração com as pessoas que apresentou correlação negativa com baixa significância. Assim, esse fator deve ser visto com atenção, uma vez que o servidor pode estar mal integrado com as pessoas por uma questão de perfil psicológico e exercício da função/lotação, especificamente no caso do servidor técnico administrativo que pode ser alocado em diferentes departamentos/setores da universidade.

Conclusivamente, esta pesquisa aponta que o momento de expansão pelo qual passa a Universidade objeto deste estudo pode ser frutífero, com tendências de bom aproveitamento do seu quadro permanente, levando-se em consideração os níveis de socialização. É sabido que esta não é a única forma de se medir a eficiência de uma instituição. Contudo, é um indicativo plausível e ainda pouco estudado e aplicado no Brasil. Lembrando que, especificamente no caso da IFESP, alguns índices ainda podem ser melhorados pelo departamento de Gestão de Pessoas, por meio de estratégias de socialização.

O observado neste estudo empírico aponta resultados relevantes para o contexto pesquisado e que devem ser considerados por outras IFES, pois suas características administrativas, processos de seleção e expansão são similares, sendo provável que os pontos negativos levantados aqui possam ser incialmente pesquisados em outros contextos. Como por exemplo, a questão do perfil psicológico e exercício da função/lotação do servidor técnico administrativo, portanto, possível pular etapas de trabalho em busca de melhorias. Esta, a principal contribuição deste artigo a outros contextos.

Como limite do trabalho, têm-se os problemas típicos aos métodos quantitativos; e seus resultados amplos e horizontalizados (PASQUALI, 2003). Dessa forma, aponta-se como agenda de pesquisas a ampliação da amostra em outras IFES. Ainda, vislumbramse investigações que incluam a utilização de métodos de pesquisa qualitativos, com o intuito de se aprofundar os conhecimentos em torno dos fenômenos da Socialização Organizacional. Nesse ínterim estudos com abordagens qualitativa e quantitativa, caracterizando-se uma triangulação de métodos, sugere-se a inserção de uma variável 
que verifique a intenção do servidor aposentar-se na instituição. Além disso, recomenda-se a realização de novos trabalhos com o ISO, inclusive uma nova aferição fatorial e/ou análise confirmatória através do método de equações estruturais, a fim de possibilitar ao Inventário tornar-se um instrumento de gestão amplamente utilizado e fiável, sobretudo no setor público.

\section{NOTAS}

${ }^{1}$ Vários autores, como Boschetti (2009), Chaves (2006), Cunha (2007b), Frigotto (2006), Mancebo (2004), Mancebo; Maués; Chaves (2006), Otranto (2004) e Santos (2004), afirmam que, nesse período, o Governo Lula dá continuidade às ações empreitadas pelo governo de Fernando Henrique Cardoso no que tange à educação pública superior. Ou seja, o governo Cardoso desenvolveu sua concepção sobre o papel da educação, especialmente da educação superior, a crescente desresponsabilização do Estado com a Universidade, através da redução de verbas públicas para seu financiamento. Assim, simultaneamente, estimulou o empresariamento deste nível de ensino sob a aparência de democratização do acesso à educação (LIMA, 2009).

${ }^{2}$ Cabe ressaltar que os escores das respostas deste fator foram invertidos, desta forma entende-se que este é um resultado positivo. Assim, seria correto denominar este fator como "Integração com a organização".

\section{REFERÊNCIAS}

ANDRADE, D. C. T. ; CASTRO, C. G. ; CAPPELLE, M. C. A. ; PEREIRA, J. R. A Gestão Pública e o REUNI: entre o Social e o Gerencial. Revista da Universidade Vale do Rio Verde, v. 9, p. 154-170, 2011.
ASHFORTH, B. E.; SLUSS, D. M.; SAKS, A. M. Socialization tactics, proactive behavior, and newcomer learning: Integrating socialization models. Journal of Vocational Behavior, Orlando, v. 70, n. 3, p. 447-462, June 2007.

BAGOZZI, R. P.; YI, Y.; PHILIPPS, L. W. Assessing construct validity in organizational research. Administrative Science Quarterly, Ithaca, v. 36, n. 3, p. 421-458, Sept. 1991.

BORGES, L. O.; SILVA, F. H. V. C.; MELO, S. L.; OLIVEIRA, A. S.; ROAZZI, A. Reconstrução e validação de um inventário de socialização organizacional. Revista de

Administração Mackenzie, São Paulo, v. 11, n. 4, p. 4-37, jul./ago. 2010.

BORGES, L. O.; ALBUQUERQUE, F. J. B. Socialização Organizacional. In: CARLOS, Z. J.; EDUARDO, B. J.; BITTENCOURT, B. A. V. (Org.). Psicologia, Organizações e Trabalho no Brasil. Porto Alegre: Artmed, 2014. 615 p.

BOSCHETTI, I. A ofensiva de desregulamentação no capitalismo contemporâneo: tendências destrutivas das reformas neoliberais no Serviço Sociall. Revista Em Pauta, Rio de Janeiro, n. 24, p. 1-19, dez. 2009.

BRASIL. Decreto $\mathbf{n}^{\mathbf{0}} \mathbf{6 . 0 9 6}$, de 24 de abril de 2007. Institui o Programa de Apoio a Planos de Reestruturação e Expansão das Universidades Federais - REUNI. Disponível em:

<http://www.planalto.gov.br/ccivil_03/_Ato2 007-2010/2007/Decreto/D6096.htm>. Acesso em: 10 dez. 2009a.

BRASIL. Decreto no 94.664, de 23 de julho de 1987. Aprova o Plano Único de Classificação e Retribuição de Cargos e Empregos de que trata a Lei ${ }^{\circ} 7.596$, de 10 de abril de 1987. Disponível em: <http://http://www.planalto.gov.br/ccivil_03/ decreto/Antigos/D94664.htm>. Acesso em: 3 
mai. 2011a.

BRASIL. Lei $\mathbf{n}^{\circ} \mathbf{1 1 . 7 8 4}$, de 22 de setembro de 2008. Dispõe sobre a reestruturação do Plano Geral de Cargos do Poder Executivo - PGPE, de que trata a Lei ${ }^{\circ}$. 11.357, de 19 de outubro de 2006; do Plano Especial de Cargos da Cultura, de que trata a Lei ${ }^{\circ}$. 11.233 , de 22 de dezembro de 2005, do Plano de Carreira dos Cargos Técnico-Administrativos em Educação, de que trata a Lei $n^{\circ} .11 .091$, de 12 de janeiro de 2005. Disponível em: < http://http://www.planalto.gov.br/ccivil_03/_a to2007-2010/2008/lei/111784.htm >. Acesso em: 3 mai. 2011d.

BRASIL. Ministério da Educação e do Desporto. Diretrizes gerais do Decreto 6096 - REUNI - Reestruturação e Expansão das Universidades Federais 2007. Disponível em: <http://portal.mec.gov.br/sesu/arquivos/pdf/di retrizesREUNI.pdf $>$. Acesso em: $10 \mathrm{dez}$. 2009b.

BRESSER-PEREIRA, L. C. Do estado patrimonial ao gerencial. In: SACHS, I.; WILHEIM, J.; PINHEIRO, P. S. (Ed.).

Brasil: um século de transformações. São Paulo: Companhia das Letras, 2001. p. 222259.

\section{CARVALHO, V. D. Resiliência e} socialização organizacional de novos servidores: um estudo transcultural. 2009. 272 p.Tese (Doutorado em Psicologia Social) - Universidade Federal do Rio Grande do Norte, Natal, 2009.

CERVO, A. L.; BERVIAN, P. A. Metodologia científica. 4. ed. São Paulo: Makron Books, 1996. 242 p.

\section{CHANLAT, J. F. et al. O indivíduo na} organização: dimensões esquecidas. São Paulo: Atlas, 1996. 204 p.

CHAO, G. T.; O'LEARY-KELLY, A. M.; WOLF, S.; KLEIN, H. J.; GARDNER, P. D. Organizational socialization: its content and consequences. Journal of Applied

Psychology, Washington, v. 79, n. 5, p. 730743, Oct. 1994.

CHAVES, V. L. J. Reforma do estado e privatização da universidade pública brasileira: consequiências sobre o trabalho docente. In: SEMINÁRIO DA REDESTRADO - REGULAÇÃO EDUCACIONAL E TRABALHO DOCENTE, 6., 2006, Rio de Janeiro. Anais... Rio de Janeiro: UERJ, 2006.p. 1-8.

COCHRAN, W. G. Sampling techniques. New York: J. Wiley, 1965. 413 p.

CUNHA, L. A. O desenvolvimento meandroso da educação brasileira entre o estado e o mercado. Educação \& Sociedade, Campinas, v. 28 , n. 100 , p. $809-829$, out. 2007b.

DURKHEIM, E. As regras do método sociológico as regras do método sociológico as regras do método sociológico. São Paulo: Companhia Editora Nacional, 1987. 1285 p.

FRIGOTTO, G. "Fundamentos científicos e técnicos da relação trabalho e educação no Brasil de hoje." Fundamentos da educação escolar do Brasil contemporâneo. Rio de Janeiro: Fiocruz/EPSJV (2006): 241-288.

HABERMAS, J. Mudança estrutural da esfera pública. Rio de Janeiro: Tempo Brasileiro, 1984. 398 p.

HAUETER, J. A.; MACAN, T. H.; WINTER, J. Measurement of newcomer socialization: construct validation of a multidimensional scale. Journal of Vocational Behavior, Orlando, v. 63, n. 1, p. 20-39, Aug. 2003.

\section{INSTITUIÇÃO FEDERAL DE ENSINO SUPERIOR PESQUISADA. REUNI. \\ Disponível em: < \\ http://www.nomedainstituicao.br/ > . Acesso em: 10 mar. 2011.}


LAKATOS, E. M.; MARCONI, M. A.

Técnicas de pesquisa: planejamento e execução de pesquisas, elaboração, análise e interpretação dos dados. 4. ed. São Paulo: Atlas, 1995. 206 p.

\section{LÉDA, D.; MANCEBO, D. REUNI:} heteronomia e precarização da universidade e do trabalho docente. Educação \& Realidade, Porto Alegre, v. 34, n. 1, p. 49-64, jan./abr. 2009.

LEVY JUNIOR, M. Socialização. In: CARDOSO, F. H.; IANNI, O. (Org.). Homem sociedade. São Paulo: Editora Nacional, 1973. 318 p.

\section{LIMA, K. Reforma da educação superior} brasileira nos anos de neoliberalismo: reformulações político-pedagógicas em curso nas universidades federais do estado do Rio de Janeiro. Rio de Janeiro: UFF/Escola de Serviço Social e Programa de Pós-Graduação em Educação, 2009. 20 p. Projeto de Pesquisa.

LIMA, L. C.; AZEVEDO, M. L. N.; CATANI, A. M. O processo de Bolonha, a avaliação da educação superior e algumas considerações sobre a universidade nova. Avaliação, Campinas, v. 13, n. 1, p. 7-36, mar. 2008.

MANCEBO, D.; MAUÉS, O.; CHAVES, V. L. J. Crise e reforma do estado e da universidade brasileira: implicações para o trabalho docente. Educar em Revista, Curitiba, n. 28, p. 37-53, jul./dez. 2006.

MANCEBO, D. Reforma universitária: reflexões sobre a privatização e a mercantilização do conhecimento. Educação \& Sociedade, Campinas, v. 25, n. 88 , p. 845 866, out. 2004.

MARINI, C. O contexto contemporâneo da gestão pública na América Latina. Revista do Servidor Público, Brasília, v. 53, n. 4, p.3152, out./dez. 2002.
MARTINS, J. de S. A exclusão social e a nova desigualdade. São Paulo: Paulus, 1997. $140 \mathrm{p}$.

MATTAR, F. N. Pesquisa de marketing: metodologia, planejamento. 5. ed. São Paulo: Atlas, 1999. 314 p.

MENDES, V. L. P. S.; TEIXEIRA, F. L. O novo gerencialismo e os desafios para a administração pública. In: ENCONTRO DA ASSOCIAÇÃO NACIONAL DOS PROGRAMAS DE PÓS GRADUAÇÃO EM ADMINISTRAÇÃO, 24., 2000, Florianópolis. Anais... Florianópolis: ANPAD, 2000. 1 CD-ROM.

MORRISON, E. W. Information usefulness and acquisition during organizational encounter. Management Communication Quarterly, New York, v. 9, n. 2, p. 131-155, Nov. 1995.

MOTTA, F. C. P. Controle social nas organizações. Revista de Administração de Empresas, São Paulo, v. 33, n. 5, p. 68-87, set./out. 1993.

OLIVEIRA, S. D. C. D.; LINO, M. A. B.; BORGES, L. D. O.; CARVALHO, V. D. D.; MELO, S. L. D.; SILVA, A. K. L. D; STEVEN, G. A socialização organizacional dos servidores da UFRN, segundo grupo ocupacional e tempo de serviço. Revista Psicologia, Florianópolis, v. 8, n. 1, p. 118141, 2008.

OSTROFF, C.; KOZLOWSKI, S. W. J. Organizational socialization: the role of information acquisition. Personnel

Psychology, Washington, v. 45, n. 4, p. 849872, Dec. 1992.

OTRANTO, C. R. A autonomia universitária como construção coletiva. In: REUNIÃO ANUAL DA ASSOCIAÇÃO DE PÓSGRADUAÇÃO E PESQUISA, 27., 2004, Caxambu. Anais... Caxambu: ANPEd, 2004. Disponível em: 
$<$ http://www.anped.org.br/REUNIoes/27/gt11

/t113.pdf >. Acesso em: 20 nov. 2009.

PASQUALI, L. Psicometria: teoria dos testes na psicologia e na educação. Petrópolis:

Vozes, 2003. 400 p.

SANTOS, B. S. A universidade no século

XXI: para uma reforma democrática e emancipatória da universidade. São Paulo: Cortez, 2004. 120 p.

SCHEIN, E. H. A psicologia organizacional. Rio de Janeiro: Prentice-Hall, 1982. 224 p.

SHINYASHIKI, G. T. O processo da socialização organizacional. In: FLEURY, M. T. As pessoas na organização. São Paulo: Gente, 2003. p. 165-184.

TAORMINA, R. J. Organizational socialization: a multidomain, continuous process models. International Journal of Selection and Assessment, New York, v. 5, n. 1, p. 29-47, Jan. 1997.

\section{TRIVIÑOS, A.N.S. Introdução à pesquisa} em ciências sociais: a pesquisa qualitativa em educação. São Paulo: Atlas, 1987. 314 p.

UNIVERSIDADE FEDERAL DA BAHIA.

Universidade nova: reestruturação da arquitetura acadêmica da UFBA. Salvador, 2007. Disponível em:

<http://www2.faced.ufba.br/noticias/noticias/ universidadenova25102006>. Acesso em: 10 dez. 2009.

VAN MAANEN, J. Processando as pessoas estratégias de socialização organizacional. In: FLEURY, M. T. L.; FISCHER, R. M.

Cultura e poder nas organizações. São

Paulo: Atlas, 1989. cap. 2, p. 45- 62.

YIN, R.K. Estudo de caso: planejamento e métodos. Porto Alegre: Bookman, 2001. 326

p. 